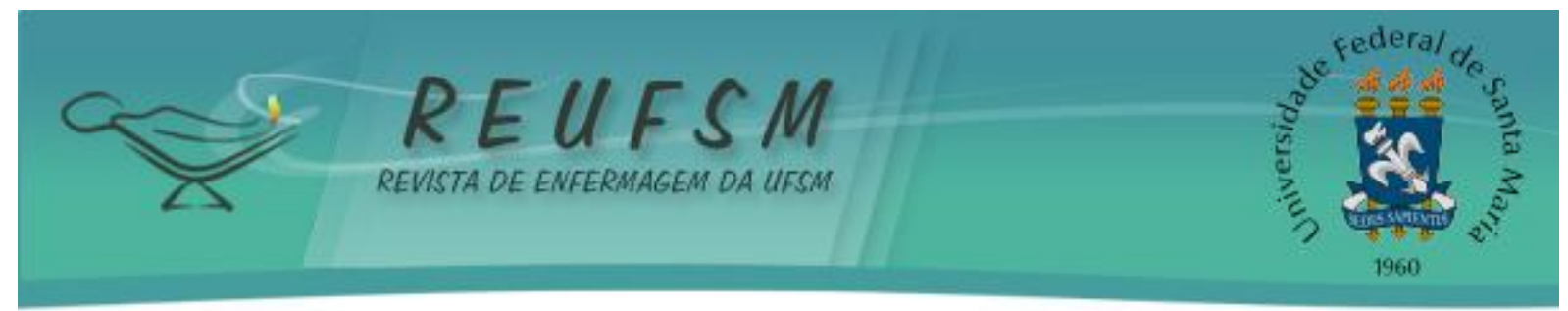

REFLEXÃO

\title{
A FORMAÇÃO DO ENFERMEIRO FRENTE ÀS NECESSIDADES EMERGENTES DA TERMINALIDADE DO INDIVÍDUO
}

\section{THE FORMATION PROCESS OF THE NURSE CONSIDERING THE EMERGING END-OF-LIFE NEEDS OF THE INDIVIDUAL}

\section{LA FORMACIÓN DEL ENFERMERO FRENTE A LAS NECESIDADES EMERGENTES DE LA TERMINALIDAD DEL INDIVIDUO}

\author{
Stefanie Griebeler Oliveira ${ }^{1}$ \\ Alberto Manuel Quintana ${ }^{2}$ \\ Maria de Lourdes Denardin Budó 3 \\ Karla Cristiane Oliveira Bertolino ${ }^{4}$ \\ Maria Henriqueta Luce Kruse ${ }^{5}$
}

RESUMO: Este artigo pretende realizar uma reflexão sobre a formação do enfermeiro, com vistas às necessidades decorrentes do enfrentamento da finitude humana. Essa discussão faz-se relevante, frente às necessidades que emergem com o processo de morte e morrer do paciente terminal. Para contemplar esta temática, foram desenvolvidos dois tópicos: o ensino fragmentado na enfermagem frente à morte, e a formação do enfermeiro à luz do paradigma dos cuidados paliativos. Desse modo, acredita-se ser necessário modificações curriculares, buscando integrar melhor as disciplinas básicas e profissionalizantes, além de criação de núcleos de estudos sobre morte, preparando, assim, o profissional de saúde para o planejamento de cuidados ao paciente terminal. Além disso, reforça-se a importância de se preparar os docentes para esta mudança.

Descritores: Enfermagem; Ensino; Educação; Morte.

ABSTRACT: This article aims to carry out a reflection about the formation process of the nurse, considering the needs of the individual who faces the end of his life. Such discussion is relevant considering the emerging needs of the process of death and dying of the terminal patient. In order to contemplate such theme, two topics were developed: the fragmented studies concerning health care carried out by nurses regarding death and the nurse formation considering the palliative care paradigm. Thus, curricular modifications are needed, aiming to improve the integration between the scientific and

\footnotetext{
${ }^{1}$ Enfermeira. Mestranda em enfermagem da Universidade Federal de Santa Maria (UFSM). Professora Substituta do Departamento de Enfermagem (UFSM). Membro dos Grupos de Pesquisa Cuidado, Saúde e Enfermagem e do Núcleo de Estudos Interdisciplinares em Saúde (NEIS) da UFSM; e do Grupo de Estudos Culturais na Educação em Saúde e Enfermagem (UFRGS). E-mail: stefaniegriebeler@yahoo.com.br

2 Psicólogo. Doutor em Ciências Sociais. Professor Associado do Departamento de Psicologia e dos Programas de Pós-Graduação em Psicologia e em Enfermagem (UFSM). Líder do Grupo de Pesquisa NEIS (UFSM). albertom.quintana@gmail.com

${ }^{3}$ Enfermeira. Doutora em Enfermagem. Professor Associado do Departamento de Enfermagem e do Programa de Pós - Graduação em Enfermagem (UFSM). Membro do Grupo de Pesquisa Cuidado, Saúde e Enfermagem (UFSM) lourdesdenardin@gmail.com

${ }^{4}$ Enfermeira. Mestre em enfermagem. Professora do Curso de Enfermagem do Centro Universitário Franciscano. Membro do Grupo de Pesquisa NEIS e do Grupo de Estudos e Pesquisas em Enfermagem e Saúde (UFSM). k.karla@live.com

${ }^{5}$ Enfermeira. Doutora em Educação. Professor Associado do Departamento de Enfermagem e do Programa de Pós-Graduação de Enfermagem (Mestrado e Doutorado) da Universidade Federal do Rio Grande do Sul (UFRGS). Líder do grupo de Estudos Culturais na Educação em Saúde e Enfermagem e membro do Núcleo de Estudo Interdisciplinar do Processo de Cuidado Humano na Saúde e na Doença (UFRGS). kruse@uol.com.br
} 


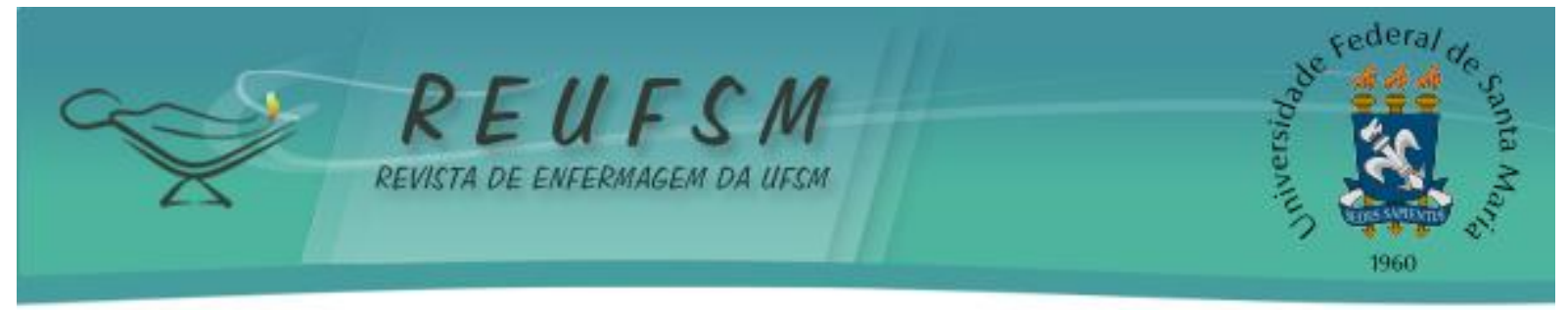

technical disciplines, besides the creation of study groups about death in order to prepare the health care professional to plan health care towards the terminal patient. Moreover, the importance of preparing teachers for such change is reinforced.

Descriptors: Nursing; Teaching; Education; Death.

RESUMEN: Este artículo pretende realizar una reflexión sobre la formación del enfermero, objetivando atender las demandas originadas del enfrentamiento de la finitud humana. Esa discusión se hace relevante frente a las necesidades que surgen en el proceso de muerte y morir del paciente terminal. Para complementar dicha temática, se desarrollaron dos tópicos: la fragmentación de la enseñanza frente a la muerte en enfermería y la formación del enfermero a luz del paradigma de los cuidados paliativos. De este modo, se piensa que es necesario ir más allá de modificaciones curriculares, buscando mejor integrar las materias técnicas y científicas. Es necesario crear núcleos de estudios sobre la muerte que preparen al profesional de la salud para la planificación de los cuidados dados al paciente terminal. Asimismo, se refuerza la importancia de preparar a los profesores para este cambio.

Descriptores: Enfermería; Enseñanza; Educación; Muerte.

\section{INTRODUÇÃO}

Os cursos da área de saúde, sobretudo os de Enfermagem, nos últimos anos têm buscado uma formação mais humanista. Contudo, os currículos, ainda, permanecem fragmentados, com disciplinas destacando predominantemente as científicas e as profissionais. Esta perspectiva pode limitar uma atenção à saúde mais humanizada, pois o profissional não consegue visualizar o ser humano em suas diferentes dimensões.

O cadáver, utilizado como instrumento didático em uma das disciplinas do curso, a Anatomia, configura um "primeiro paciente", além de um encontro com um "corpo morto". Isto, facilmente, pode construir uma visão de que o paciente é algo para ser visto e não ouvido, produzindo, assim, os corpos frios. Estes podem ser entendidos como despojados de identidade, facilitando o acesso e a manipulação daqueles que cuidam desses corpos. ${ }^{1}$ Ademais, os sentimentos originados pelos encontros com o cadáver não são comentados, nem pelos alunos nem pelos professores, gerando angústias, que tendem a ficar "retidas", produzindo assim, mecanismos de defesa, como a negação da morte.

A cultura de negação da morte está fortemente presente na sociedade ocidental. ${ }^{2}$ Assim, diante dos avanços tecnológicos e da ênfase na formação dos profissionais para a preservação da vida, a morte passou a ser considerada um fracasso pelos profissionais de saúde. ${ }^{3}$

Com o advento do paradigma que propõe a atenção humanizada à saúde, busca-se a inclusão da família no processo de cuidado, bem como a autonomia do paciente e seus familiares frente às decisões terapêuticas. Contudo, o ensino fragmentado pode dificultar a implementação dessa perspectiva humanizadora, em especial, a proposta de cuidados paliativos, uma modalidade de atendimento ao indivíduo que se encontra no final da vida, acometido por uma doença fora de possibilidades terapêuticas.

Nessa perspectiva, conforme as necessidades que surgem em torno da assistência de cuidados paliativos, o currículo acadêmico fragmentado produz múltiplas lacunas, tais como a dificuldade de conceber o paciente como um todo indissolúvel. Apesar de que nos últimos anos, houve avanços nos currículos, no sentido de uma visão mais globalizada, o desafio que ainda se apresenta, é a articulação dos conhecimentos para a atenção integral do paciente e uma maior reflexão sobre os enfrentamentos da finitude do ser humano. Diante dessas considerações, questiona-se: como articular a formação profissional, 


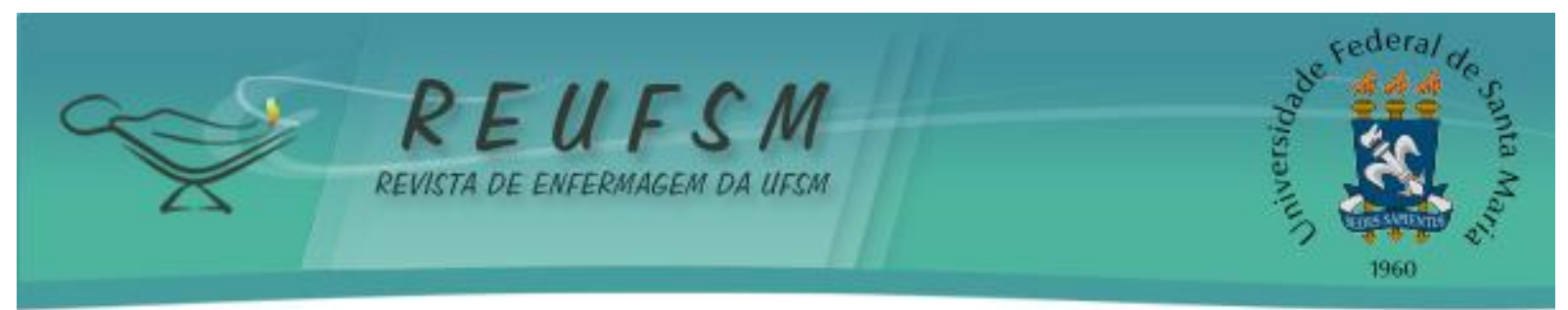

efetivada de maneira fragmentada, com as necessidades emergentes que recomendam o enfrentamento da morte como processo natural da vida humana?

São desses pontos de reflexão que parte este artigo. 0 enfermeiro era formado, principalmente, com o objetivo de ajudar o paciente a viver, a todo o custo e quaisquer ônus, instalando, assim, uma luta permanente contra a morte. Contudo, na atualidade, quando se pretende acompanhar o processo da morte e do morrer dos doentes terminais, o enfermeiro tem começado a entender e atender suas necessidades, "ajudando-os" a morrer dignamente. Dessa forma, neste artigo, propõe-se realizar uma reflexão sobre a formação do enfermeiro com vistas às necessidades decorrentes do enfrentamento da finitude humana.

\section{RESULTADOS}

Para contemplar a temática da formação do enfermeiro com vistas às necessidades emergentes da terminalidade do indivíduo, foram desenvolvidos dois tópicos: o ensino fragmentado na enfermagem frente à morte, e a formação do enfermeiro à luz do paradigma dos cuidados paliativos.

\section{0 ensino fragmentado na enfermagem frente à morte}

Uma das primeiras disciplinas do curso de enfermagem é a Anatomia, a qual utiliza o cadáver como seu objeto de estudo. Este cadáver pode produzir certo sofrimento diante da morte, e também estabelecer o primeiro contato com o "paciente", aqui representado pelo corpo morto. Acredita-se que este "primeiro paciente" pode determinar uma cisão em múltiplos âmbitos, denotando algo para ser visto e manuseado, e não ouvido $^{1}$, e, por conseguinte, a futura relação do profissional com o paciente poderá ser prejudicada no futuro, já que, inicialmente, se designa a ideia de observar, e não ouvir.

Os sentimentos originados nas aulas de anatomia, não são comentados, conjuntamente, pelos acadêmicos ${ }^{4}$, devido ao receio de ouvir de um professor ou colega, que não está no lugar certo ou esse não pode ser um profissional de saúde. ${ }^{5}$ Essas experiências "desconfortáveis", relacionadas tanto às disciplinas básicas como com as profissionalizantes, não são discutidas pelos profissionais de saúde, podendo refletir uma forma de defesa frente à inevitabilidade da morte. ${ }^{4}$ Desse modo, ao retirar a identidade humana do cadáver e, posteriormente, do paciente que está vivo, mas pode morrer, evitase viver a angústia de pensar que aquele corpo foi, um dia, um ser humano hígido. ${ }^{6}$

Nesse caminho, a fragmentação do ensino em pequenas disciplinas que olham para o corpo transformando-o em órgãos, tecidos e células, portanto destituídos de humanidade, atua contribuindo para a dessensibilização de elementos que possam lembrar a inexorabilidade da morte. ${ }^{6}$ Juntamente com isso, a formação dos profissionais de saúde, ainda, é direcionada para a promoção, recuperação e preservação da vida, deixando-os, por conseguinte, despreparados, para os enfrentamentos referentes à morte, a partir do entendimento de que ela não faz parte da vida. ${ }^{7}$ Além disso, o currículo carece de uma disciplina que teorize as questões da morte e do morrer de forma aprofundada e reflexiva.

Assim, essa aparente falta de abordagem da morte, durante o curso, revela-se como sendo uma estratégia, mesmo que inconsciente, de preparar o aluno para lidar como a morte de uma maneira particular: a negação. ${ }^{8}$ Com efeito, a disciplina de anatomia, ofertada no início do curso pode ser um bom exemplo dessa intencionalidade. 0 aluno iniciante, ao deparar-se com um cadáver, é inundado por inúmeras sensações, todas as quais, muitas vezes, são ignoradas pelo docente da disciplina. Desse modo, ao aluno, 


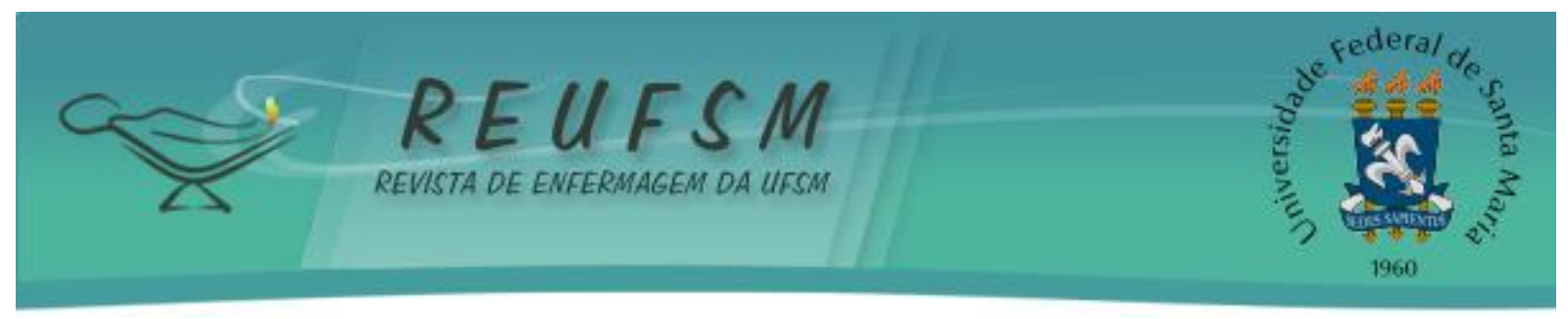

desde o início, está se transmitindo que a forma de lidar com a morte é a negação, pois um bom profissional não pode se deixar afetar pela morte do outro.

Em um estudo bibliográfico ${ }^{4}$ foram encontradas quatro abordagens da morte pela enfermagem, as quais foram organizadas em períodos de dominância. A primeira delas, "a morte silenciada e ocultada", entre os anos de 1937 a 1979, no qual a enfermeira não podia se envolver ou demonstrar sentimentos. A segunda, quando a enfermeira estabelece uma luta contra a morte, que marcou o período de 1980 a 1989. Neste período, a enfermagem, especialmente em unidades de terapia intensiva, começa a presenciar a morte rotineiramente, mas, com a possibilidade de prolongamento da vida a partir do emprego de inúmeros aparatos tecnológicos. No período de 1990 a 1999, denominado "a morte em cena: multiplicidade de facetas", os enfermeiros eram questionados sobre o término da vida, desvelando mecanismos de defesa, tais como a negação e a racionalização, utilizadas para enfrentar o cuidado ao paciente terminal, por meio de um relacionamento frio, rotinizado e regulado. Por fim, entre 2000 a 2005, aborda-se a morte e os cuidados paliativos, apresentados como mudança de paradigma assistencial no contexto do cuidado no fim da vida, que considera a morte como um processo natural. ${ }^{4}$

Os cuidados paliativos são dirigidos a pacientes portadores de doença, fora de possibilidades terapêuticas de cura, e às suas famílias, a fim de melhorar sua qualidade de vida proporcionando conforto através do controle de sintomas apresentados pelo paciente. Além disso, essa prática entende a morte como parte da vida. ${ }^{9}$ Enfatiza-se, que o enfermeiro precisa reconhecer que quando não há metas de cura ao paciente terminal, há as metas do cuidado $^{10}$, sempre havendo algo a fazer a este indivíduo. Em suma, se faz necessário obter serenidade e equilíbrio para enfrentar as tensões que envolvem o processo de morrer, além de promover os cuidados que supram as necessidades do doente terminal. ${ }^{11}$

\section{A formação do enfermeiro à luz do paradigma dos cuidados paliativos}

Em grande parte dos cursos de formação em enfermagem, a temática da morte ocupa um espaço mínimo no currículo, reduzindo-se aos cuidados com o corpo postmortem. Não é destinada uma abordagem teórica significante sobre a morte, em que haja inclusão dos aspectos socioculturais que permeiam este fenômeno. ${ }^{7}$ Embora isto tenha sido constatado em um determinado curso de enfermagem, acredita-se que estas perspectivas sejam uma realidade predominante na formação deste profissional.

Essa forma de organização do ensino é, de certa forma, motivo de insatisfação identificada em estudo realizado com docentes de enfermagem, o qual desvelou o tabu da morte intrínseco ao cotidiano profissional, demonstrando o reconhecimento da fragilidade do enfrentamento da morte por parte dos enfermeiros. ${ }^{7}$ Tal fato, é encontrado em outro estudo, realizado com enfermeiros docentes da UTI, que demonstrou que a morte de um paciente, durante o turno de estágio, desencadeia dificuldades de enfrentamento, pelo sentimento de responsabilidade, e, também, pela insegurança do aluno frente ao fenômeno da finitude humana. ${ }^{12}$ Outros estudos com acadêmicos de enfermagem, revelaram o sentimento de despreparo frente à morte, devido a pouca discussão sobre ela no curso, o qual enfatiza a técnica, refletindo, mais uma vez a perspectiva acadêmica fragmentária. ${ }^{13}$

Se, por um lado, há necessidade de dar voz aos medos e angústias em torno do fenômeno morte, a fim de proporcionar discussões no cotidiano profissional, bem como no processo de formação acadêmica, ${ }^{74}$, por outro, observa-se a enorme dificuldade de operacionalizar esse tipo de medida. De fato, em outro estudo ${ }^{15} \mathrm{com}$ docentes de enfermagem, acerca da morte, mostra que a proposta de discussão sobre a temática é 


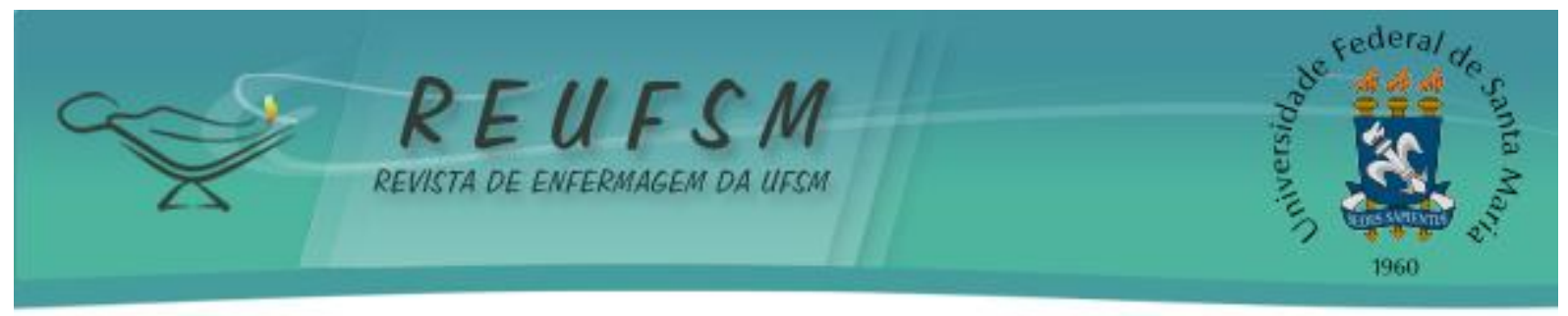

referida, mas que se enfrentam dificuldades para sua sistematização e efetivação no cotidiano acadêmico e profissional.

Entretanto, outro estudo, revelou que para educar para a morte e o morrer não basta criar novas disciplinas e reformular currículos. Estas são estratégias importantes, contudo não são suficientes; faz-se necessário mudar o enfoque sobre o processo de morrer e possibilitar que docentes e discentes compreendam a existência humana em sua singularidade e pluralidade. ${ }^{14}$

\section{CONSIDERAÇÕES FINAIS}

Diante das reflexões e discussões expostas neste trabalho, considera-se que um dos primeiros passos para melhorar a formação do enfermeiro frente à morte seria a integração das disciplinas básicas e profissionalizantes, no intuito de articular os conhecimentos entre ambas. Para que essa premissa seja efetivada, são necessárias mudanças no currículo, partindo de discussões dos projetos políticos pedagógicos dos cursos. No entanto, esta não seria a única estratégia.

Outra recomendação seria a atitude do professor, pautada no respeito aos cadáveres, recordando ao aluno que há uma história de vida por trás das peças anatômicas dispostas no laboratório. Isto possibilitaria certa sensibilidade para com o ser humano e o cuidado humanizado a ser ofertado a ele, evitando os equivocados sentimentos de onipotência sobre a morte. Ademais, uma aproximação com o ser humano, com vistas a identificar e compreender a sua totalidade, desde os primeiros semestres, também seria outra forma de articular os conhecimentos adquiridos, fato que, felizmente, já vem acontecendo em algumas universidades.

A inclusão de referenciais teóricos sobre a morte compondo um tema transversal nas disciplinas do currículo para a formação do enfermeiro seria uma das alternativas a ser seguida, desde que tais temas não se reduzam ao preparo do corpo, e abordem os aspectos socioculturais e históricos que abarcam a morte.

Diante da associação entre as dificuldades dos docentes e dos discentes, as quais se apresentam semelhantes, acredita-se que a estratégia de realização de grupos, núcleos de estudos e discussões, acerca da morte e do morrer, se consolidariam em momentos de troca de informações e construção de conhecimentos pertinentes para ambos. Tais discussões promoveriam uma atenção mais integral, um entendimento da morte como inerente à vida, e um planejamento do cuidado com perspectiva de conforto.

Portanto, refletindo sobre a formação do enfermeiro para o cuidado de doentes terminais, aconselha-se que as alterações curriculares incluam temas transversais que contemplem a morte e o morrer, organizando-se um currículo que se invista contra a fragmentação que o caracteriza. Por outro lado, reforça-se a importância de preparar os docentes para esta importante mudança.

\section{REFERÊNCIAS}

1. Kruse MHL. Os poderes dos corpos frios: das coisas que se ensinam às enfermeiras. Brasília (DF): ABEn; 2004.

2. Hennezel M. A morte no centro da vida. In: Hennezel M, organizadora. Morrer de olhos abertos. Cruz Quebrada: Casa das Letras; 2006. p.55-73.

3. Oliveira AC, Sá L, Silva MJP. O posicionamento do enfermeiro frente à autonomia do paciente terminal. Rev Bras Enferm. 2007; 60(3):286-90. 


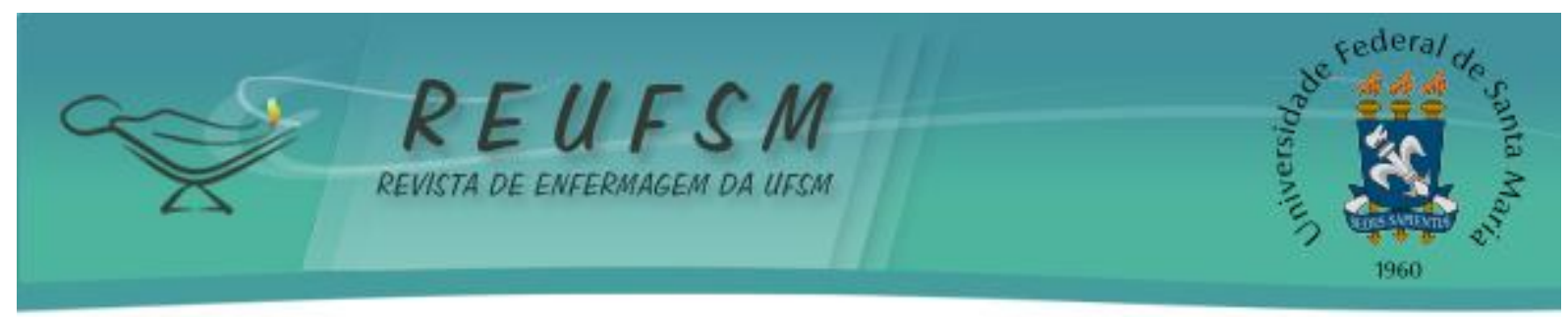

4. Silva KS, Ribeiro RG, Kruse MHL. Discursos de enfermeiras sobre morte e morrer: vontade ou verdade? Rev Bras Enferm. 2009;62(3):451-6.

5. Zaidhaft S. Morte e formação médica. Rio de Janeiro: Francisco Alves; 1990.

6. Kovács MJ. Educação para a morte: desafio na formação de profissionais de saúde e educação. São Paulo: Casa do Psicólogo/FAPESP; 2003.

7. Bellato R, Araújo AP, Ferreira HF, Rodrigues PF. A abordagem do processo do morrer e da morte feita por docentes em um curso de graduação em enfermagem. Acta Paul Enferm. 2007;20(3):255-63.

8. Quintana A, Rodrigues AT, Goi CMD, Bassi LA. Humanização e estresse na formação médica. Revista AMRIGS. 2004;48(1):27-31.

9. Brasil. Ministério da Saúde. Instituto Nacional do Câncer. Cuidados paliativos oncológicos: controle de sintomas. Rio de Janeiro: INCA; 2001.

10. Avanci BS, Carolindo FM, Góes FGB, Netto NPC. Cuidados paliativos à criança oncológica na situação do viver/morrer: a ótica do cuidar em enfermagem. Esc Anna Nery Rev Enferm. 2009;13(4):708-16.

11. Míguez Burgos A, Muñoz Simarro D. Enfermería y el paciente en situación terminal. Enferm glob. 2009;16:1-9.

12. Guedes GF, Ohara CVS, Silva GTR. Processo de ensinar e aprender em UTI: um estudo fenomenológico. Rev Bras Enferm. 2008;61(6): 828-34.

13. Bernieri J, Hirdes A. O preparo dos acadêmicos de enfermagem brasileiros para vivenciarem o processo morte-morrer. Texto Contexto Enferm. 2007;16(1):89-96.

14. Pinho LMO, Barbosa MA. A morte e o morrer no cotidiano de docentes de

Enfermagem. Rev enferm UERJ. 2008;16(2):243-8.

15. Carvalho MDB, Valle ERM. Vivência da morte com o aluno na prática educativa. Cienc Cuid e Saúde. 2006;5(supl.):26-32.

Data de recebimento: $13 / 09 / 2010$

Data de aceite: 10/11/2010

Contato com autora responsável: Stefanie Griebeler Oliveira

E-mail: stefaniegriebeler@yahoo.com.br. 